\title{
Center for Disease Control and Prevention Classification System for HIV- Infected Adults and Adolescents Clinical Classification
}

National Cancer Institute

\section{Source}

National Cancer Institute. Center for Disease Control and Prevention Classification

System for HIV-Infected Adults and Adolescents Clinical Classification. NCI Thesaurus. Code $C 124715$.

A standardized rating scale developed and revised by the Centers for Disease Control and Prevention (CDC) in 1993, which is a classification system used to assess the severity of HIV disease based on CD4 cell counts and the presence of specific HIV-related conditions. 